\title{
Correlation of regional densitometry patterns, radiological appearances, and pulmonary function tests in chronic bronchitis and emphysema
}

\author{
G. R. SUTHERLAND, R. HUME, and W. B. JAMES \\ Southern General Hospital, Glasgow \\ M. DA VISON a d J. KEN NEDY \\ Department of Clinical Physics and Bio-engineering, Western Regional Hospital Board, Glasgow
}

In 20 male patients suffering from chronic bronchitis and emphysema investigated by pulmonary $x$-ray densitometry, five different types of densitometer trace pattern were observed during the FEV manoeuvre, which appeared to be related to the degree of zonal airway obstruction and the radiological severity of emphysema. We thought some of the features of the traces were caused by displacement of blood from the area of the lung being examined by trapped alveolar air at a pressure exceeding those in the surrounding blood vessels. A close correlation $(\mathrm{P}<0.001)$ was found between the conventional $\mathrm{FEV}_{1}$ and the pulmonary densitometer score derived from summated regional observations made during the FEV manoeuvre. A similar high degree of correlation was observed between the $\mathrm{FEV}_{1}$ and a score based on regional radiological appearances. Correlations between $\mathrm{PaO}_{2}$ and $\mathrm{PaCO}_{2}$ and the densitometer and $x$-ray scores were of doubtful significance. The findings indicate that critical evaluation of the radiological features of the pulmonary vessels in patients with emphysema is useful in assessing the overall degree of airway obstruction. Regional densitometer pattern analysis is a valuable contributory method of investigating these patients and the results of a comparison of these two methods suggest that it may be possible to distinguish between larger and smaller airway obstruction.

At the present time, methods of investigating regional ventilation include bronchospirometry, bronchial catheterization with mass spectrometry, and isotope scanning and counting techniques. Pulmonary $x$-ray densitometry may also be used and several groups of workers (Andrews, Jensik, and Pfisterer, 1959; Steiner, Laws, Gilbert, and McDonnell, 1960; Kourilsky, Marchal, and Marchal, 1962; Oderr, 1964; Laws and Steiner, 1965; Zelefsky, Schulz, and Freeman, 1970; Sutherland, Leask, and Samuel, 1968) have described the use of the method in various lung disorders. In several of these reports reference has been made to changes in the densitometry traces in patients with airway obstruction which have been attributed to air trapping and have taken the form of a displacement of the densitometer trace indicating increased $x$-ray translucency of the lung during expiration. It is the purpose of the present study to investigate these changes more fully in a group of patients suffering from chronic bronchitis and emphysema and to correlate the findings with abnormalities in the radiological appearances and blood gas determinations.

\section{SUBJECTS AND METHODS}

Twenty male patients aged 37-65 (mean 54) years diagnosed as suffering from chronic bronchitis and emphysema by the usual clinical criteria were studied (M.R.C., 1965). The presence of emphysema was deduced on the basis of clinical and radiological observations. The disease was of various degrees of severity and this was documented by forced expiratory volume in 1 second $\left(F^{2} V_{1}\right)$ and forced vital capacity (FVC) observations on Vitalograph apparatus. In 16 patients, arterial oxygen $\left(\mathrm{PaO}_{2}\right)$ and carbon dioxide $\left(\mathrm{PaCO}_{2}\right)$ tensions were also measured using a micro-Astrup $N$ machine. After clinical assessment the patients had a standard postero-anterior film of the chest taken and subsequently densitometry was carried out in the supine position.

DENSITOMETRY TECHNIQUE Observations were made in four corresponding zones in each lung: in the infraclavicular region; at the level of the upper and lower parts of the hilum; and at the base of each lung. A two-channel linear densitometer was used so that changes in corresponding zones in each lung could be recorded simultaneously (Leask and Sutherland, 1966; $\mathbb{\mathbb { D }}$ Sutherland et al., 1968). Calibration was carried out at the beginning of each patient's study with an 
aluminium step wedge and also during each regional observation when a single millimetre of aluminium was introduced between the patient and the densitometer sensors. Duplicate recordings of the densitometer trace during an FEV manoeuvre were made from each pair of corresponding zones. In order to correlate the timing of densitometry changes with alterations in tracheal air flow, a thermistor air flow detector was inserted into a Perspex tube with an internal diameter of one inch through which the patient was asked to breathe: $x$-ray screening factors were $80 \mathrm{kV}$ and 0.5 $\mathrm{mA}$, giving a skin dose rate of approximately 500 mrad per minute. Once the densitometer sensors had been positioned for each observation the $x$-ray beam was collimated to a minimum field size. The total screening time was usually between 2 and 3 minutes.

Interpretation of densitometer traces Inspection of the FEV densitometer traces from each zone revealed that they could be grouped broadly into five distinct types (Fig. 1). On the basis of the amount of reversal of the densitometer trace, i.e., an upward displacement during expiration, indicating increasing translucency instead of the expected downward movement of the trace, it was possible to arrange them in an order which appeared to be related to the degree of expiratory difficulty. Code numbers were given to the different types of trace so that increasing trace reversal was indicated by a large number. It can be seen that the type 5 trace demonstrates inspiratory as well as expiratory trace reversal.

Interpretation of radiographs Two of the authors (G.R.S. and W.J.) examined the radiographs independently, each on two separate occasions, and allotted a code number ( 1 to 4 ) indicating the severity
T A B L E I

OBSERVER AGREEMENT IN X-RAY CODE VALUE ALLOCATION

\begin{tabular}{|c|c|}
\hline Degree of Agreement between Observers & No. of Zones \\
\hline $\begin{array}{l}\text { Complete agreement on all four readings } \\
\text { Mean coding of each observer identical } \\
\text { Mean coding differs by up to one code point ... } \\
\text { Mean coding differs by up to two code points } \\
\text { Mean coding differs by over two code points .. }\end{array}$ & $\begin{array}{r}54 \\
10 \\
72 \\
19 \\
5\end{array}$ \\
\hline
\end{tabular}

T A B L E I I

X-RAY EMPHYSEMA CODE AND SCORE VALUES

\begin{tabular}{c|c}
\hline $\begin{array}{c}\text { Code/Score } \\
\text { Values }\end{array}$ & Radiological Appearances \\
\hline 1 & $\begin{array}{c}\text { Normal } \\
\text { Minimal alteration of normal topography of } \\
\text { middle and smaller size vascular markings } \\
\text { Severe changes as '2' with reduction in size and } \\
\text { number of peripheral lung markings } \\
\text { Recognizable air spaces of 1.0 cm or more in } \\
\text { diameter }\end{array}$ \\
\hline 4
\end{tabular}

of emphysematous change in each of the eight densitometer zones in each patient (Table I). There was good agreement between the two series of observations made by each observer. G.R.S. gave the same coding to $117(73 \%)$ and W.J. to $123(77 \%)$ of the 160 zones. Table II shows the degree of agreement between the observers in allocating the $x$-ray code. In view of the subjective nature of the procedure it was accepted that, for the purpose of the study, agreement between the observers should be considered to be present if the mean code value of each observer's readings did not differ by more than one code point. In such cases, the higher mean value was taken as the code for that zone. Using these criteria, there was agree-

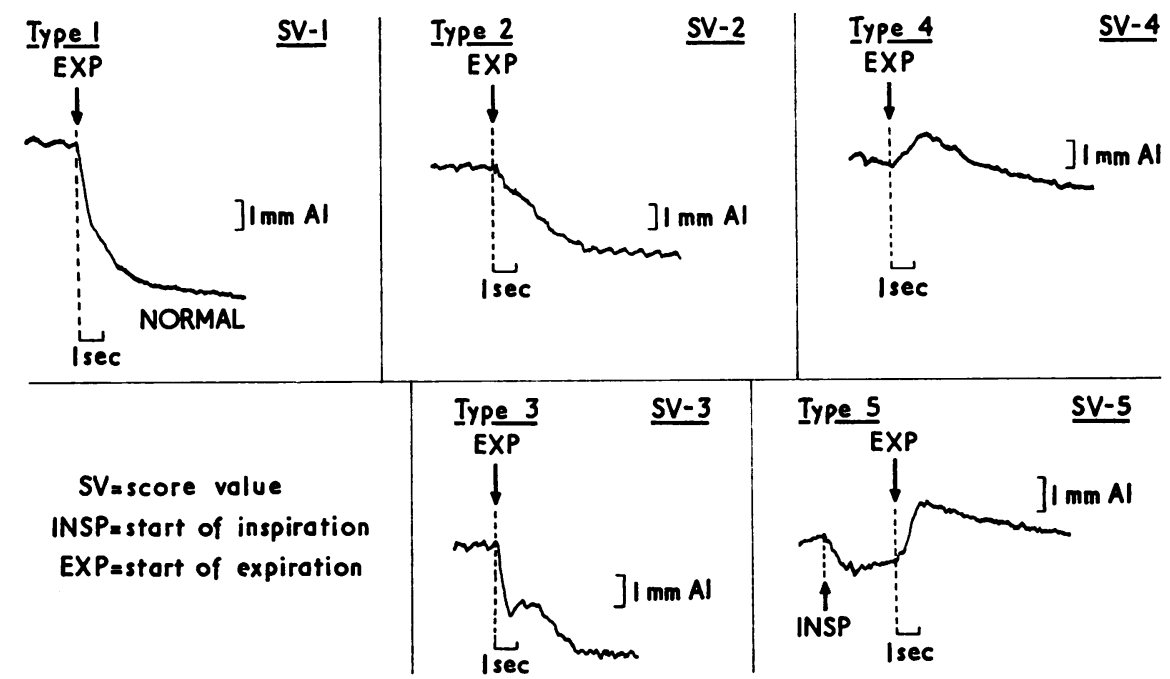

FIG. 1. FEV densitometer trace types and score values. 
ment between the observers in $85 \%$ of the zones. In 19 other zones, the difference in mean code values of the two observers did not exceed two code points, and in five it was greater than two points. These zones were reviewed by both observers together and agreed coding values were obtained.

Densitometer and $x$-ray scores for each patient were obtained by summing the appropriate code values.

\section{RESULTS}

Mean values and ranges of the results of the pulmonary function tests obtained in the study are shown in Table III.

\section{T A B L E I I I}

RANGES AND MEAN VALUES OF RESPIRATORY FUNC. TION TESTS OF ALL PATIENTS

\begin{tabular}{|c|c|c|c|c|c|c|}
\hline & & & & & Range & Mean \\
\hline $\begin{array}{l}\mathrm{FEV}_{1} \text { (litres) } \\
\mathrm{FVC}^{\text {(litres) }} \\
\mathrm{PaO}_{\mathbf{3}} \text { (mmHg) } \\
\mathrm{PaCO}_{2} \text { (mmHg) }\end{array}$ & $\begin{array}{l}\cdots \\
\cdots\end{array}$ & $\begin{array}{l}\cdots \\
\cdots \\
\cdots\end{array}$ & $\begin{array}{l}\ldots \\
\cdots \\
\cdots\end{array}$ & $\begin{array}{l}\cdots \\
\cdots \\
\cdots\end{array}$ & $\begin{array}{c}0 \cdot 7-3 \cdot 0 \\
1 \cdot 3-4 \cdot 3 \\
60-94 \\
33-45\end{array}$ & $\begin{array}{l}1 \cdot 7 \\
2 \cdot 8 \\
85 \\
39\end{array}$ \\
\hline
\end{tabular}

COMPARISON OF FEV 1 WITH DENSITOMETER AND $x$-RAY SCORES These relationships were studied in order to test the validity of the $x$-ray densitometer scoring (Figs 2 and 3). In both cases the results are highly significant $(\mathrm{P}<0.001)$. It is evident, therefore, that there is a close relationship between the overall degree of radiological abnormality, the summated abnormalities of the densitometer trace, and the extent of airway obstruction as indicated by the $\mathrm{FEV}_{1}$ in each patient.

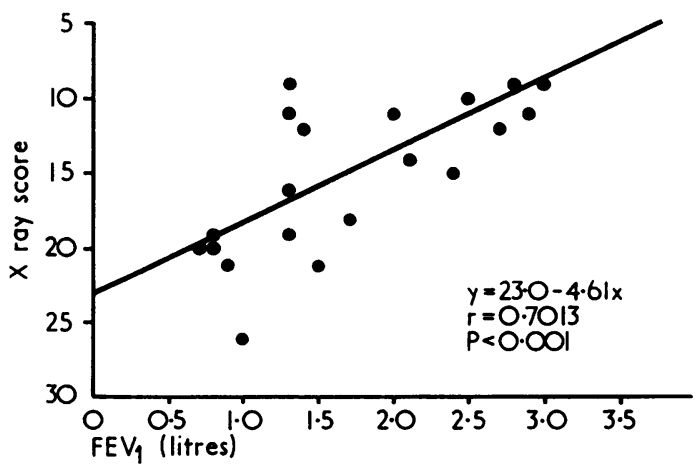

FIG. 2. Relationship between $\mathrm{x}$-ray score and forced expiratory volume in 1 second.

REGIONAL COMPARISON OF $x$-RAY APPEARANCES AND DENSITOMETER PATTERNS (TABLE IV) In this table, individual lung zones have been categorized according to their $x$-ray code and the type of densitometer trace. No allowance has been made for the position

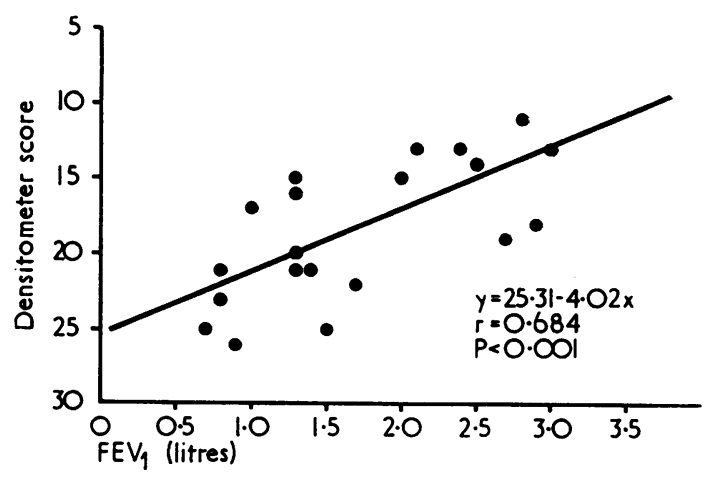

FIG. 3. Relationship between densitometer score and forced expiratory volume in 1 second.

of the zone within the lung and each zone has been taken as though it was standing alone and uninfluenced by adjacent zones. In the last two columns of the table, densitometer trace patterns 2 and 3 , representing moderate abnormality, and trace patterns 4 and 5 , indicating severe abnormality, have been taken together and expressed as percentages of the total number of zones in each radiological grouping. It can be seen that whereas the $(2+3)$ percentages are largely similar in all radiological groups, there is a progressive increase in the $(4+5)$ percentage from $5 \%$ in the ' 1 ' $x$-ray grouping to $40 \%$ in the ' 5 ' grouping.

\section{T A B L E I V}

RELATION BETWEEN X-RAY CODE AND DENSITOMETER TRACE TYPE IN 160 PULMONARY ZONES

\begin{tabular}{|c|c|c|c|c|c|c|c|c|}
\hline \multirow{2}{*}{$\begin{array}{c}X \text {-ray } \\
\text { Code }\end{array}$} & \multicolumn{5}{|c|}{ Densitometer Trace Types } & \multirow{2}{*}{$\begin{array}{c}\text { Types } \\
2+3 \\
\%\end{array}$} & \multirow{2}{*}{$\begin{array}{c}\text { Types } \\
4+5 \\
\%\end{array}$} & \multirow{2}{*}{ Total } \\
\hline & 1 & 2 & 3 & 4 & 5 & & & \\
\hline $\begin{array}{l}1 \\
2 \\
3 \\
4\end{array}$ & $\begin{array}{r}26 \\
10 \\
5 \\
0\end{array}$ & $\begin{array}{r}29 \\
16 \\
8 \\
7\end{array}$ & $\begin{array}{r}8 \\
21 \\
5 \\
2\end{array}$ & $\begin{array}{l}3 \\
4 \\
4 \\
4\end{array}$ & $\begin{array}{l}0 \\
4 \\
2 \\
2\end{array}$ & $\begin{array}{l}56 \\
67 \\
54 \\
60\end{array}$ & $\begin{array}{r}5 \\
15 \\
25 \\
40\end{array}$ & $\begin{array}{l}66 \\
55 \\
24 \\
15\end{array}$ \\
\hline
\end{tabular}

RELATION OF ARTERIAL $\mathrm{O}_{2}$ AND $\mathrm{CO}_{2}$ TENSIONS TO DENSITOMETER AND $\boldsymbol{x}$-RAY SCORES The P value was $\mathcal{O}$ less than 0.05 in both these relationships; however, as only 16 patients had blood gas determinations, the significance of these correlations is doubtful despite the $P$ value.

\section{DISCUSSION}

In the present paper the close relationship between the $\mathrm{FEV}_{1}$ and the densitometer score indicates that regional densitometer pattern analysis gives a useful semiquantitative assessment of zonal airway obstruction. 
What is the likely mechanism of the reversals seen in some of the densitometer traces? During the FEV manoeuvre it is probable that many of the patients caused their general intrathoracic pressure to rise above the pulmonary venous and capillary pressure levels. In regions of the lung prevented from expiring readily by airway obstruction, the increase in pressure of the air trapped in this way would tend to displace blood from adjacent vascular channels to areas of the lung not subjected to the same level of pressure, i.e., areas communicating more freely with the larger central airways.

Let us now consider the four abnormal trace patterns. In type 2, the appearance of the trace is similar to that of the conventional low rate FEV record with no evidence of reversal, suggesting the least amount of obstruction of the airways. The type 3 curve shows a normal early descent but this is succeeded by reversal believed to be related to the build-up of pressure within the peripheral airway system as the bronchi and bronchioles narrow during expiration. In the type 4 trace, no evidence of early descent is seen; reversal begins at the start of expiration. This is considered to be the result of an immediate blocking of some of the airways leading from the zone being examined, causing an elevation of the pressure in the distal air spaces and compression of the vascular bed. As the expiratory manoeuvre continues, however, in some cases a slow descent of the trace develops and eventually it falls below the inspiratory level. It seems likely that this is due to the ultimate success of the sustained expiratory effort in producing expulsion of the trapped and pressurized air either into the bronchial tree or by collateral air drift into adjoining alveolar spaces leading to increased radiological density.

The type 5 trace is thought to indicate an even greater degree of airway obstruction. Such traces show complete reversal of the normal respiratory cycle appearances. At the beginning of inspiration the lung density increases and this is sustained during breath holding until the moment of expiration when again reversal occurs and increased translucency of the lung develops. In this situation it appears that the obstruction is of such severity that the act of inspiration is insufficient to open the airways and allow the normal entry of air to the more peripheral parts of the lung. Inspiration may well result in this case in the diversion of blood into the affected part of the lung, accounting for its relative increase in radiological density. It has been suggested by Oderr (1964) that the reversal of the densitometer trace is due to paradoxical ventilation or 'pendelluft' (Otis et al., 1956). As the densitometer observations in this study were made during the FEV manoeuvre which was undertaken after a short period of breath holding at maximum inspiratory level, the pressure gradient in the airways in favour of lagging, out of phase, lung units is minimized before expiration begins. At the moment forced expiration is initiated, this residual pressure gradient is presumably almost immediately reversed by the rapidly rising intrathoracic pressure. In these circumstances it is unlikely that paradoxical ventilation can exist for more than a very short time at the outset of expiration and therefore would not explain the sustained trace reversals seen in the present study.

The correlation between radiological appearances and pathological studies of the lungs in emphysema has been well documented in the past (Reid and Simon, 1959; Laws and Heard, 1962; Reid and Millard, 1964). Recently, Nairn, Prime, and Simon (1969) have demonstrated that there is a relationship between the radiological appearances of emphysema and the degree of ventilatory impairment. In the present series a similar relationship between the radiographic findings and the $\mathrm{FEV}_{1}$ has been observed although the method of radiological interpretation is rather different from that of Nairn et al. (1969) and is confined to alterations in the vascular pattern and the occurrence of bullæ in the lungs. A comparison of these radiological features with the densitometer traces on a zonal basis is shown in Table IV. The occurrence of a generally similar proportion of less severe densitometer trace abnormality (type 2 and 3 traces) in all the radiological groups indicates that the mechanism of these traces is evidently independent of changes revealed by the radiograph and therefore may be related primarily to disease of the larger airways. By contrast, the increase in percentage of type 4 and 5 traces in the zones showing increasing radiological disease appears to relate more severe functional abnormality with the presence of advanced emphysema and therefore with more peripheral bronchiolar disease (Hogg, Macklem, and Thurlbeck, 1968).

Although in the majority of lung zones there is a reasonably close relationship between the severity of radiological changes and the degree of abnormality of the densitometer trace, in others the correlation is less satisfactory. For example, in three 'normal' (code 1) and eight slightly abnormal (code 2) radiological zones (Table IV), there is evidence of severe functional abnormality. These discrepancies are almost certainly due to the 
inadequacy of radiographic methods in demonstrating all but the more severe forms of emphysema (Reid and Millard, 1964) and illustrate the complementary value of densitometry in assessing the regional distribution and severity of pathophysiological changes in the lung. The remaining zones are those which show severe radiological abnormality (codes 3 and 4 ) and yet have normal (type 1) or near normal (type 2) densitometer traces. The explanation of these findings is more conjectural but it is believed that they may result from a failure to achieve a sufficiently high intrathoracic pressure during the forced expiratory manoeuvre to induce the hæmodynamic changes considered to be responsible for the densitometer trace reversal.

The poor correlations between the densitometer and $x$-ray scores and the $\mathrm{PaO}_{2}$ and $\mathrm{PaCO}_{2}$ observations are not altogether surprising as these values are clearly dependent not only upon ventilatory function but upon ventilation-perfusion ratios. Recently, Shibel and Moser (1970) observed a similar lack of relationship between ventilatory observations and arterial blood gas measurements.

The correlation of the $x$-ray score and the $\mathrm{FEV}_{1}$ in this study suggests that careful examination of the vascular shadows in patients with emphysema gives an indication of the degree of their ventilatory impairment. The contributory value of densitometer studies in assessing areas of the lung which show no radiological abnormality has also been demonstrated. The ease of carrying out densitometer studies without disturbing the function of the respiratory system and the developing interest in distal airway disease (leading article, B.M.J., 1971) suggests that the technique may soon enjoy increased popularity.

\section{REFERENCES}

Andrews, A. H. Jr., Jensik, R., and Pfisterer, W. H. (1959). Fluoroscopic pulmonary densiography. Dis. Chest, 35, 117.
British Medical Journal (1971). Leading article. Disorders of the distal airways. 1, 63 .

Hogg, J. C., Macklem, P. T., and Thurlbeck, W. M. (1968). Site and nature of airway obstruction in chronic obstructive lung disease. New Engl. J. Med., 278, 1355.

Kourilsky, R., Marchal, M., and Marchal, M. T. (1962). A ஜे new method of functional X-ray exploration of the lungs: photoelectric stati-densigraphy. Dis. Chest, 42, 345 .

Laws, J. W., and Heard, B. E. (1962). Emphysema and the chest film. A retrospective radiographic and pathological study. Brit. J. Radiol., 35, 750.

- and Steiner, R. E. (1965). X-ray densitometry in the study of pulmonary ventilation and the pulmonary circulation. Brit. J. Radiol., 38, 512.

Leask, E., and Sutherland, G. R. (1966). A simple fluorodensitometer for observing changes in the X-ray density of the lungs. Bio-med. Engng., 1, 395.

Medical Research Council (1965). Definition and classification of chronic bronchitis for clinical and epidemiological purposes. Lancet, 1, 775.

Nairn, J. R., Prime, F. J., and Simon, G. (1969). Association between radiological findings and total and regional function in emphysema. Thorax, 24, 218.

Oderr, C. (1964). Air trapping, pulmonary insufficiency and fluordensimetry. Amer. J. Roentgenol., 92, 501.

Otis, A. B., McKerrow, C. B., Bartlett, R. A., Mead, J., McIlroy, M. B., Selverstone, N. J., and Radford, E. P. (1956). Mechanical factors in the distribution of pulmonary ventilation. J. appl. Physiol., 8, 427.

Reid, L., and Millard, F. J. C. (1964). Correlation between radiological diagnosis and structural lung changes in emphysema. Clin. Radiol. 15, 307.

- - and Simon, G. (1959). Pathological findings and radiological changes in chronic bronchitis and emphysema. Brit. J. Radiol., 32, 291.

Shibel, E. M., and Moser, K. M. (1970). The relation between spirometric measurements and arterial blood gas analysis in patients with chronic airflow obstruction. Thorax, 25, 598.

Steiner, R. E., Laws, J. W., Gilbert, J., and McDonnell, M. J. (1960). Radiological lung-function studies. Lancet, 2, 1051 .

Sutherland, G. R., Leask, E., and Samuel, E. (1968). Pulmonary vascular and ventilatory changes in bronchial carcinoma studied by fluorodensitometry. Clin. Radiol., 19, 269.

Zelefsky, M. N., Schulz, R. J., and Freeman, L. M. (1970). Assessment of regional lung function and its clinical applications by the combined use of lung scan and gamma densigraphy. Radiology, 94, 167. 